\title{
Needle Insertion in Laparoscopic Thermoablation of the Liver
}

\author{
Eisele RM*, Gäbelein G and Glanemann M \\ Department of general Vascular \& Pediatric Surgery, University of the Saarland, Germany
}

Submission: July 09, 2017; Published: July 21, 2017

"Corresponding author: Robert M Eisele, Department of general Vascular \& Pediatric Surgery, Saarland University, Homburg, 66123 Saarbrücken, Germany, Email: robert.eisele@uks.eu

\section{Background}

Local ablation of malignant liver tumors is considered an established treatment modality with curative intention for irresectable disease. Recently, laparoscopic access has been suggested because of presumed advantages for diagnosis and effectiveness. In a recently published retrospective study, improved local tumor control as well as prolonged disease-free survival could be confirmed for laparoscopic in comparison to percutaneous microwave coagulation therapy (MCT) using multivariate analysis [1]. Occasionally, percutaneous needle placement and precise targeting of the tumor is difficult in laparoscopic MCT. The following article is meant to illustrate technical options, which are available for laparoscopic MCT.

\section{Free Hand Punction}

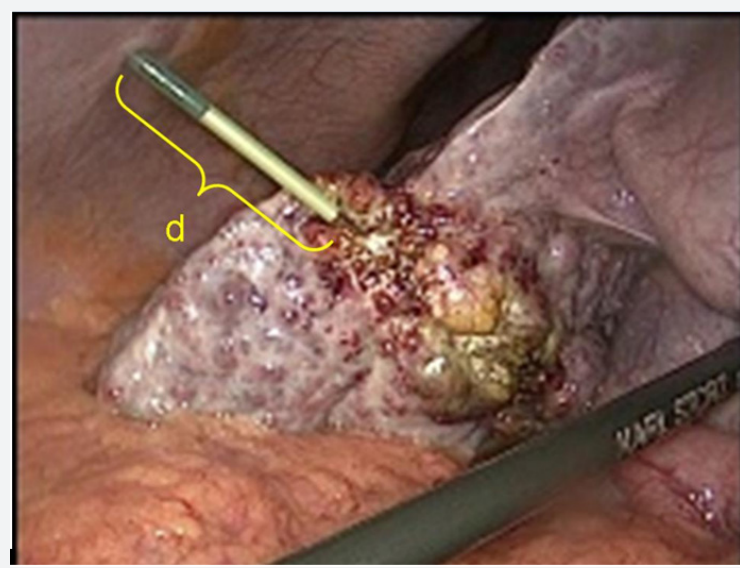

Figure 1: Laparoscopic microwave coagulation therapy of a hepatocellular carcinoma using a $14 \mathrm{G}$ probe Type 6203-MWAProbe-14.1 (Med Waves Inc. Ave Cure ${ }^{\mathrm{TM}}$, San Diego, CA, U.S.A.). Note the short way from the abdominal wall to the superficially sited tumor ( $d=$ distance, each scale-line resembles $2 \mathrm{~cm}$.

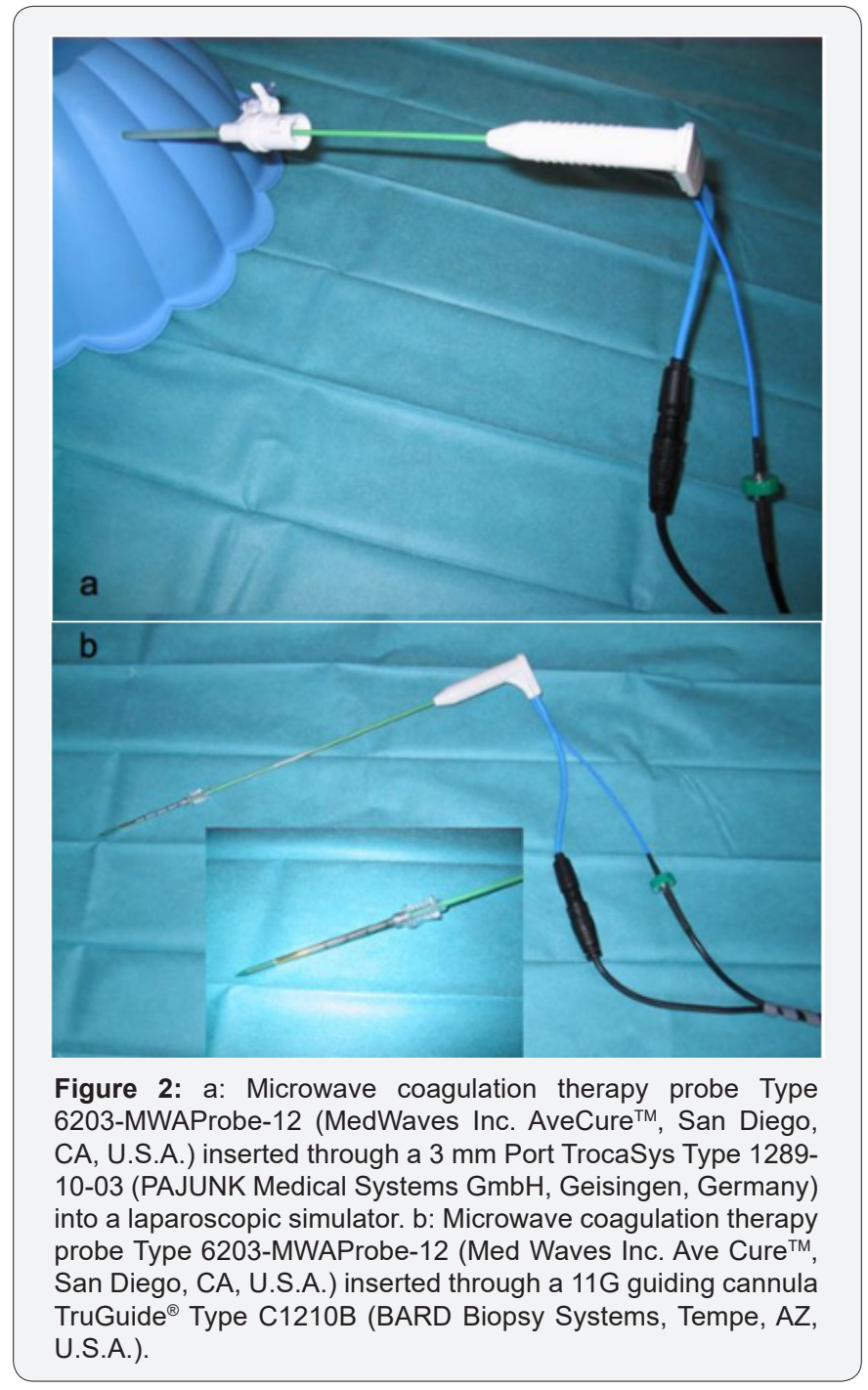

In analogy to a targeted biopsy under ultrasound control in the liver, laparoscopic MCT can likewise be performed by 
percutaneously inserting the MCT applicator and positioning the needle under ultrasound control into the tumor center, using laparoscopic ultrasound (LUS). In case of a short needle path, the MCT antennas ranging from 14 to $16 \mathrm{gg}$, are usually sufficiently rigid to allow correction of the direction of the needle tip, if not prevented by too much adipose tissue. In corpulent patients or longer needle paths for other reasons, the cutaneous needle entry impairs the freedom of movement for the needle, and control of the needle tip is lost. For this reason, stabilization of the needle entry is needed. Amer et al. [2] suggested the use of a hollow needle with a bore of slightly larger diameter than the MCT device A $14 \mathrm{~g}$ microwave antenna requires a $13 \mathrm{~g}$ coaxial needle, a $16 \mathrm{~g}$ antenna a $15 \mathrm{~g}$ needle. This may however lead to a distinct loss of pneumoperitoneum, which is avoided if a standard laparoscopy trocar is used in combination with a laparoscopic MCT device. A $12 \mathrm{~g}$ MCT applicator with $30 \mathrm{~cm}$ shaft length is available for use with a $3 \mathrm{~mm}$ standard trocar. The diameter and length of the MCT device is obviously larger than the figures interventionalists are familiar with (Figure 1) illustrates a laparoscopic free hand MCT. Figure 2 shows the $12 \mathrm{~g}$ MCT antenna with a $3 \mathrm{~mm}$ trocar as well as with a $13 \mathrm{~g}$ coaxial needle in the laparoscopy simulator.

\section{Guided Punction}

The technical difficulty of free hand punction consists in three-dimensional control of the needle path and ultrasound probe resembling the cross section shown by the ultrasound image. In order to eliminate one degree of freedom, in analogy to percutaneous procedures, distinct devices for needle guidance have been developed. A simple solution consists in a groove at the margin of the ultrasound probe, where the MCT needle slides along. The probe was inserted using a $15 \mathrm{~mm}$ standard trocar and had a straight forward view. The MCT needle has been introduced besides the ultrasound probe and parallely inserted. Tsuchida et al. [3] describe this technique in detail. The limitations are however obvious: Due to the fixed geometry of the forward-looking probe and the axial access to the target area, the technique is best applied to the ventral and caudal parts of the liver. One of the paramount advantages of laparoscopic MCT in comparison to percutaneous approach-access to all parts of the liver-is thereby compromised. Retaining this advantage requires a flexible endoscopic ultrasound probe with a customized guidance channel. At date, only two producers offer laparoscopic ultrasound devices with guidance option for use with laparoscopic MCT. The maximum needle diameter is $14 \mathrm{~g}$. The maximal freedom of movement is achieved with a flexible MCT antenna.

Three elements are distinguished in such a device:

i. The rigid tip of the needle enables the insertion into the liver and tumorous tissue.

ii. The flexible shaft makes the point of insertion at the liver surface independent of the site of the cutaneous entry.

iii. The end of the shaft connects it to the cables.
In the conventional rigid devices, this part represents the handle. To date, flexible devices for radiofrequency ablation (RFA) as well as for MCT are available. Precisely, these devices are semiflexible with a 7 (MCT) to 12 (RFA) $\mathrm{cm}$ long rigid part at the tip of the needle and a 10 (RFA) to 43 (MCT) cm long flexible shaft. The composition of the semiflexible RFA device as well as the function of the LUS probe with needle guidance is described by Figure 3 .

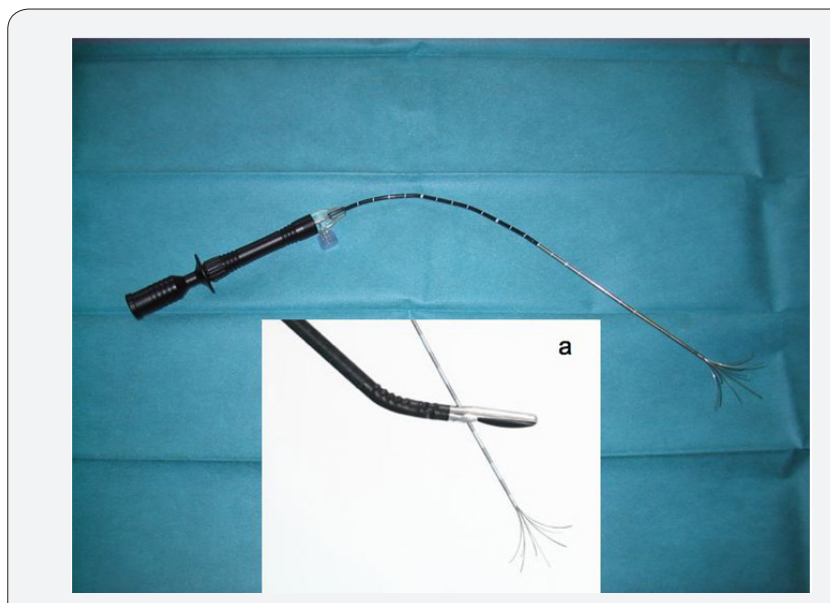

Figure 3: Flexible radiofrequency ablation needle Star Burst ${ }^{\circledR}$ Semi-Flex (Angio Dynamics, Latham, NY, U.S.A.), a: Laparoscopic ultrasound probe Type 8666-RF (bk medical ApS, Herlev, Denmark) with a radiofrequency ablation device StarBurst $^{\circledR}$ XL (Angio Dynamics, Latham, NY, U.S.A.) Image by courtesy of bk medical.

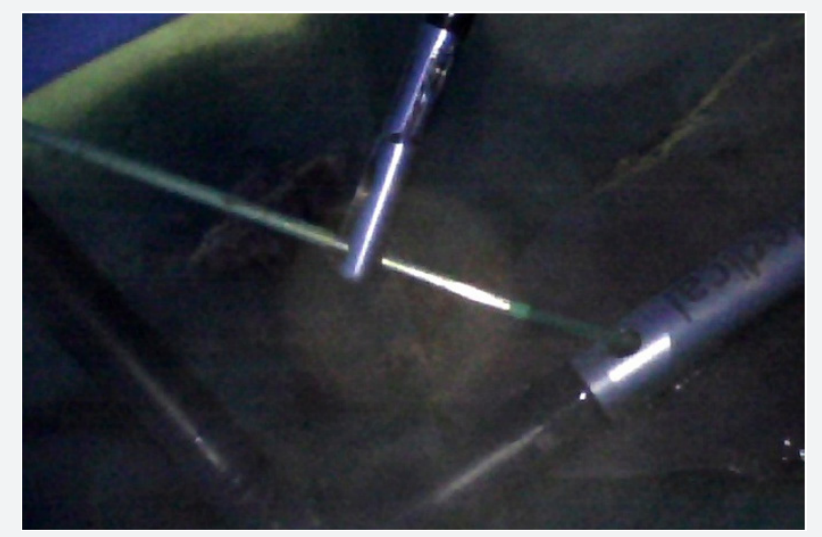

Figure 4: Laparoscopic view at the needle placement in the laparoscopy simulator in the moment the forceps grasps the tip of the semiflexible MCT antenna Type 6203-MWAProbe-16F50 (Med Waves Inc. Ave Cure ${ }^{\mathrm{TM}}$, San Diego, CA, U.S.A.).

The semiflexible applicators are inserted into the abdomen independently of the extant laparoscopic trocars and separately moved toward the liver using a special forceps with a gap in each jaw. The rigid part of the needle is grabbed and inserted into the guidance channel of the ultrasound probe. The needle path is visualized in the ultrasound image. Due to the high frequency in LUS resulting in superior spatial resolution of the ultrasound image, malpositioning of the needle is limited to less than $2 \mathrm{~mm}$ distance from the tumor center [4]. Results obtained by this technique are superior to those of percutaneous interventions 
[1]. Figure 4 gives a laparoscopic view at the needle placement in the laparoscopy simulator.

\section{Conclusion}

Laparoscopic thermoablation provides some theoretical advantages over percutaneous interventions whilst preserving minimal-invasiveness. The technical issues however challenge the surgeon and demand her/his skills in working with all the technical devices required for a successful procedure [5].

For a technically successful laparoscopic ablation, various easy-to-learn techniques are available:

i. Rigid applicators are inserted using a coaxial needle or a standard trocar for free hand placement.

ii. LUS probes with guidance in combination with flexible/ semiflexible applicators allow access to complex localizations into the liver for accurate and precise targeting of the tumors. Laparoscopic ablation with appropriate material and devices is easy to learn and results in superior local tumor control and outcome.

\section{References}

1. Eisele RM, Denecke T, Glanemann M, Chopra SS (2014) Minimalinvasive microwave coagulation therapy for liver tumors: laparoscopic and percutaneous access. Zentralbl Chir 139(2): 235-243.

2. Amer A, Strickland A, White S (2012) A simple stabilising technique for laparoscopic microwave ablation of liver tumours. Ann R Coll Surg Engl 94(2): 134.

3. Tsuchida S, Fukumoto T, Toyokawa A, Awazu M, Kusunoki N, et al. (2012) Novel Non-Trocar Technique for Laparoscopic Radiofrequency Ablation. Dig Dis 30(6): 588-591.

4. Chopra SS, Schmidt SC, Wiltberger G, Denecke T, Streitparth F, et al. (2011) Laparoscopic radiofrequency ablation of liver tumors: comparison of MR guidance versus conventional laparoscopic uoltrasound for needle positioning in a liver phantom model. Minim Invasive Ther Allied Techno 20: 212-217.

5. Eisele RM (2016) Advances in local ablation of malignant liver lesions. World J Gastroenterol 22(15): 3885-3891.

\section{Your next submission with JuniperPublishers will reach you the below assets}

- Quality Editorial service

- Swift Peer Review

- Reprints availability

- E-prints Service

- Manuscript Podcast for convenient understanding

- Global attainment for your research

- Manuscript accessibility in different formats

( Pdf, E-pub, Full Text, audio)

- Unceasing customer service

Track the below URL for one-step submission https://juniperpublishers.com/online-submission.php 